\title{
Continence Rate and Oncological Feasibility after Total Transurethral Resection of the Prostate as an Alternative Therapy for the Treatment of Prostate Cancer: A Pilot Study
}

\author{
Hee Jong Jeong, Dong Deuk Kwon ${ }^{1}$ \\ Department of Urology, Institute of Wonkwang Medical Science, Wonkwang University School of Medicine, Iksan; \\ ${ }^{1}$ Department of Urology, Chonnam National University Medical School, Gwangju, Korea
}

\begin{abstract}
Purpose: The value of total transurethral resection of prostate cancer (TURPC) as an alternative therapy was first recognized by Hans J. Reuter. Thus, we conducted the study of prospectively collected data to verify total TURPC as an alternative therapy forlocalized prostate cancer.

Methods: From January 2008 to July 2011, 14 patients with a mean age of 76.1 years (range, 66 to 89 years) with clinically localized prostate cancer were treated by prostatic resection by the corresponding author with curative intention.

Results: The mean duration of TURPC was 51.7 minutes (range, 30 to 120 minutes) and the mean amount of prostatic tissue resected was $21.2 \mathrm{~g}$ (range, 5 to $66 \mathrm{~g}$ ). An intra- and/or postoperative blood transfusion was necessary in 2 cases. Hyponatremia was found in 7 patients. Six months after TURPC, 3 cases of grade 1 and 1 case of grade 2 incontinence were observed. Three patients in the high-risk group did not achieve a prostate specific antigen (PSA) nadir of $\leq 0.2 \mathrm{ng} / \mathrm{mL}$. PSA recurrence occurred in one case in our series. Newly developed lymph node or distant metastases were not observed during the follow-up period.

Conclusions: According to our results, transurethral resection for prostate cancer can be performed with reasonable oncological results. The PSA nadir levels, and rates of biochemical failure and postoperative complications, including incontinence, were comparable with the published results for other procedures. TURPC is also inexpensive and non-invasive, and requires short hospitalization and a short surgical time without vesicourethral anastomosis.
\end{abstract}

Keywords: Urinary incontinence; Transurethral resection of prostate; Prostatic neoplasms; Prostate-specific antigen

\section{INTRODUCTION}

The "gold standard" of prostate cancer treatment is now open, laparoscopic, or robot assisted laparoscopic prostatectomy with seminal vesiculectomy, and if indicated, staging lymphadenectomy. However, these procedures are not suitable for all patients due to several factors, including their high surgical invasiveness, risk for aged patients and those with comorbidities, and expense. Several alternative treatments, such as high-intensity focused ultrasound (HIFU), transurethral microwave thermotherapy, cryotherapy, and brachytherapy have been developed. However, the existence of a satisfactory alternative method with the potential to achieve complete cancer control was not conclusively proven prior to this study [1-7].

As with open, laparoscopic, or robot assisted laparoscopic prostatectomy, a complete resection of the prostate gland including cancerous tissues can be achieved using total transurethral resection of prostate cancer (TURPC) as an alternative therapy was first recognized by Hans J. Reuter. This can be complemented by simultaneous laparoscopic staging lymphadenectomy and seminal vesiculectomy. Thus, we conducted this study to verify total TURPC with related complications as an
Corresponding author: Hee Jong Jeong

Department of Urology, Wonkwang University School of Medicine and

Hospital, 344-2 Sinyong-dong, Iksan 570-711, Korea

Tel: +82-63-859-1332 / Fax: +82-63-842-1455

E-mail: uro94c@wonkwang.ac.kr

Submitted: October 11, 2011 / Accepted after revision: December 6, 2011
This is an Open Access article distributed under the terms of the Creative Commons Attribution Non-Commercial License (http://creativecommons.org/licenses/by-nc/3.0/) which permits unrestricted non-commercial use, distribution, and reproduction in any medium, provided the original work is properly cited. 
alternative therapy for localized prostate cancer.

\section{MATERIALS AND METHODS}

The study began in January 2008 and ended in July 2011, approved by Institutional Review Board. A total of 14 patients with a mean age of 76.1 years (range, 66 to 89 years) treated by TURPC were included in this study. Neoadjuvant hormonal therapy was administered in 5 cases to reduce total prostate volume for a shorter operating time. The patients included in this study had proven localized prostate cancer of clinical stage T1-T3a by 2002 American Joint Committee on Cancer tumor, node, metastasis stage, based on histological analysis, preoperative staging by digital rectal examination, International Prostate Symptom Score, maximal flow rate, transrectal ultrasound, prostatespecific antigen (PSA) levels, bone scan, abdomen and pelvic computed tomography (CT), and chest X-ray. Preoperatively detected metastases or treatment by radiotherapy resulted in exclusion from the study. This is a pilot study conducted for the first time in Korea. Therefore, most of the patients were aged over 70 years with or without comorbidity, and thus were not suitable candidates for conventional radical prostatectomy. The patients were stratified into the following 3 risk groups: low risk (clinical stage, T1a-T2a; preoperative PSA level, $\leq 10 \mathrm{ng} / \mathrm{mL}$; and biopsy Gleason score, $\leq 6$ ), intermediate risk (clinical stage, T2b-T2c; preoperative PSA level, 10 to $20 \mathrm{ng} / \mathrm{mL}$; and biopsy Gleason score, 7), and high risk (clinical stage, T3a; preoperative PSA level, > $20 \mathrm{ng} / \mathrm{mL}$; or biopsy Gleason score, 8 to 10 ) [8].

We administered prophylactic antibiotics by intravenous injection 30 minutes before surgery. All patients were operated on under spinal or epidural anesthesia. Irrigating fluid level did not exceed $60 \mathrm{~cm}$ above the symphysis of the patient in the lithotomy position. Five patients had been receiving neoadjuvant hormonal treatment with bicalutamide and luteinizing hormone releasing hormone. Monopolar transurethral resection of prostate (TURP) was performed with a 26-Fr continuous flow resectoscope (Karl Storz GmbH \& Co. KG, Tuttlingen, Germany) using Urosol (CJ, Seoul, Korea). The maximum electrical output of the resectoscope was limited to $140 \mathrm{~W}$ for cutting and 80 $\mathrm{W}$ for clotting. At the end of the monopolar TURPC, a 22-Fr 3-way urethral Foley catheter with an inflated $50 \mathrm{~mL}$ balloon was inserted, and gentle traction was maintained at about $250 \mathrm{~g}$ for 4 hours. Continuous saline irrigation was performed until the urine draining from the urethral Foley catheter became clear in the absence of irrigation. Patients were usually discharged on the second postoperative day. The transurethral catheter was removed on the seventh postoperative day in our outpatient department.

Follow-up assessments, with serum PSA testing, rectal examination, and transrectal ultrasound, were given every 3 months in the first and second year, then every 6 months with $\mathrm{CT}$ and bone scans once a year for the first 5 years. Subsequent follow-up visits took place once a year.

\section{RESULTS}

The 14 patients undergoing total TURPC were aged 66 to 89 years (mean age, 76.1 years). The mean duration of TURPC was 51.7 minutes (range, 30 to 120 minutes), and the mean amount of resected prostatic tissue was $21.2 \mathrm{~g}$ (range, 5 to $66 \mathrm{~g}$ ). The number of patients in each risk group, based on pretreatment PSA level, biopsy Gleason score, and clinical stage (Table 1), were as follows: low risk, 1 ; intermediate risk, 6; and high risk, 7.

Perioperative complications are listed in Table 2. An intraand/or postoperative blood transfusion was necessary in 2 cases. Endoscopic examination for bleeding was not required. There was no need in any of the cases to perform open surgery due to complications of the total TURPC. Hyponatremia was found in 7 patients. Bladder neck contracture requiring sound dilatation occurred in 1 case. Incontinence was classified into 3 grades according to the Stamey scale. Six months after TURPC, 3 cases of grade 1, 1 case of grade 2, and 0 cases of grade 3 incontinence were observed.

Table 1. Perioperative characteristics of patients

\begin{tabular}{ll}
\hline Variable & Value \\
\hline No. of cases & 14 \\
Mean age (yr) & 76.1 \\
Mean follow-up (mo) & 17.9 \\
Low risk & $1(7.1 \%)$ \\
Intermediate risk & $6(42.9 \%)$ \\
High risk & $7(50 \%)$ \\
Very high risk & $0(0 \%)$ \\
Prostate weight (g) by TRUS & $27.1 / 51.9$ \\
transitional zone/total) & \\
Average mass of tissue resected (g) & 21.2 \\
Average surgery time (min) & 51.7 \\
\hline
\end{tabular}

TRUS, transrectal ultrasound. 
Table 2. Perioperative complications

\begin{tabular}{ll}
\hline Complications & \multicolumn{1}{c}{ Value } \\
\hline Transfusion & $2(14.3)$ \\
Revision by hemorrhage & $0(0)$ \\
Retroperitoneal fluid leakage & $1(7.1)$ \\
Hyponatremia & $7(50.0)$ \\
Incontinence & \\
Grade 1 & $3(21.4)$ \\
Grade 2 & $1(7.1)$ \\
Grade 3 & $0(0)$ \\
Postoperative metastatic spread & $0(0)$ \\
Bladder neck contracture & $1(7.1)$ \\
Urethral stricture & $0(0)$ \\
\hline
\end{tabular}

Values are presented as no. of patients (\%).

Three patients in the high-risk group did not achieve a PSA nadir of $\leq 0.2 \mathrm{ng} / \mathrm{mL}$. The Prostate Cancer Guidelines Panel of the American Urological Association recommend defining biochemical recurrence after radical prostatectomy as an initial serum PSA level of $0.2 \mathrm{ng} / \mathrm{mL}$ or greater, with a second confirmatory PSA level greater than $0.2 \mathrm{ng} / \mathrm{mL}$ [9]. PSA recurrence occurred in 1 case in our series.

Postoperatively, 7 patients, including the 3 who did not achieve a PSA nadir of $\leq 0.2 \mathrm{ng} / \mathrm{mL}$ and 1 with biochemical recurrence, received adjuvant hormonal therapy. Newly developed lymph node or distant metastases were not observed during the follow-up period.

\section{DISCUSSION}

Open, laparoscopic, or robot assisted laparoscopic prostatectomy is unsuitable for many patients, for reasons including age, general high-risk factors, prior prostate surgery, obesity, and socioeconomic factors such as religious restrictions or poverty. Analyses of alternative methods such as HIFU, transurethral microwave thermotherapy, cryotherapy, and brachytherapy have been published, but with follow-up times of $<10$ years and low case numbers. These assessments were therefore of limited value. A PSA nadir of $0.2 \mathrm{ng} / \mathrm{mL}$ can be achieved or not after 6 months. This may not necessarily indicate a radical character of these process $[1-7,10]$.

As with conventional surgery, a complete resection of the prostate gland, including cancerous tissues, can be achieved using total TURPC under any circumstances. The boundaries of

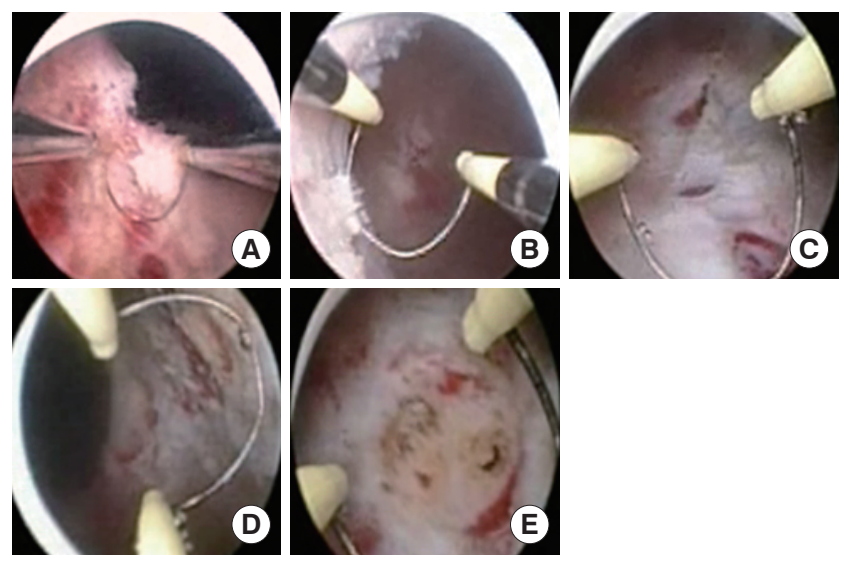

Fig. 1. Tissue structures surrounding the resected area. (A) Bladder neck fascia, (B) external sphincter fiber, (C) posterior prostatic fascia, (D) anterior prostatic fascia, (E) ejaculatory ducts.

the prostate capsule, the bladder neck, and the membranous urethra can be identified with the aid of video image magnification (Fig. 1).

Reuter et al. [11,12] performed a laparoscopic staging lymphadenectomy in patients at potential risk of cancer and a life expectancy of $>10$ years. Patients who have tumors in the preserved seminal vesicle or lymph nodes may not experience a PSA nadir of $\leq 0.2 \mathrm{ng} / \mathrm{mL}$ postoperatively, and will require adjuvant hormonal therapy with or without laparoscopic seminal vesiculectomy or lymphadenectomy. However, we have only given adjuvant hormonal therapy in 3 cases with a PSA nadir $>0.2 \mathrm{ng} / \mathrm{mL}$ because of aged patients, comorbidities and the refusal of invasive intervention.

For prostate cancer focal therapy, 4 modalities appear to have the most clinical promise: HIFU, cryotherapy, radiation therapy, and photodynamic therapy [13]. If patients with localized prostate cancer are suitable candidates for focal therapy, we can choose the partial TURPC as an alternative procedure. In our experience, we performed right-side TURPC as a focal therapy in a case of prostate cancer confined within the right lateral lobe. Impotence and incontinence are the major side effects of surgical treatment of prostate cancer. This is due to the vulnerability of the nerve plexus and blood vessels supplying the periprostatic tissue, sphincter, and penis [14]. Accordingly, the transurethral approach to the prostate is optimal because the periprostatic tissue, containing the neurovascular bundles, remains intact. The electrical current through the tissue is limited to 140 $\mathrm{W}$ for cutting and $80 \mathrm{~W}$ for clotting. The tissue is coagulated and cut without the formation of necrosis and with less depth, thus protecting the neurovascular bundle. We reduce the elec- 
trical current when applying the resectoscope to the external sphincter muscle.

Irrigation is needed to clarify the surgical field, and since the cutting is done by electricity, the irrigating fluid should be free of electrolytes. However, transurethral resection carries the risk of TUR syndrome caused by irrigation fluid absorption. The increase in dynamic and static pressure increases the risk of fluid absorption, which must be avoided to prevent TUR syndrome and the spread of prostate cancer cells $[14,15]$. Reuter et al. reported that the key to circumvent such problems is to use low-pressure irrigation with an irrigation fluid level less than 20 $\mathrm{cm}$, and preferably $10 \mathrm{~cm}$ above the pubic region using a suprapubic trocar. Thus, the capsule can be resected without being limited by the need for a short surgical time or by prostate weight; the absorption of fluid through capsular perforations is prevented; and blood loss is reduced by a better and more spontaneous control of arterial and venous bleeding [11-15]. TUR syndrome was defined as a serum sodium level of 125 $\mathrm{mmol} / \mathrm{L}$ or less after TURP with 2 or more symptoms or signs of TUR syndrome, such as nausea, vomiting, bradycardia, hypotension, hypertension, chest pain, mental confusion, anxiety, paresthesia, and visual disturbance. TUR syndrome did not occur, but hyponatremia was seen in 7 cases in our series. This was treated easily using intravenous furosemide injection with or without $3 \% \mathrm{NaCl}$ solution. Due to inexperience, we used irrigation fluid at $60 \mathrm{~cm}$ above the symphysis of the patient without a suprapubic trocar. This may increase fluid absorption into the venous plexus. Our policy was to keep the resection time as short as possible and to not exceed 60 minutes. We consider that a prostate volume of less than $50 \mathrm{~mL}$, as determined by transrectal ultrasound was sufficient to ensure safe, fast operation of this procedure.

Reuter et al. $[11,12]$ conducted a second surgical session at 8 to 12 weeks to reduce the risk of positive margins in the remnants of the prostate, similar to the re-transurethral resection of bladder tumor procedure for bladder cancer. In general, local recurrences can also be resected with a new biopsy as the primary option before radiation or antiandrogen therapy. We did not have a second surgical session in this series. In 3 cases where a PSA nadir of $\leq 0.2 \mathrm{ng} / \mathrm{mL}$ was not achieved until 12 weeks after the operation, adjuvant hormonal therapy was administered because of older age and comorbidity.

Reuter et al. [11,12] performed pathological staging during surgery, taking samples in the following order: the 3 lobes one by one, the verumontanum, the 2 dorsal quadrants of the true capsule (at 6 to 9 and 3 to 6 of the endoscopic clock), the seminal vesicles, the terminal portion of the vas deferens, the prostatic pedicles at 5 and 7 , and the 2 ventral quadrants of the capsule (at 9 to 12/12 to 3 of the endoscopic clock). However, we chose not to perform frequent fractional extraction of the tissue in order to speed up operation time. Therefore, the exact histological stages of tumors in this case series could not be shown.

Incontinence is caused by damage to the nerves and/or is a result of a preoperatively existing pelvic floor weakness. A direct violation of the external sphincter muscle is unlikely with careful surgery $[14,15]$. Although the mean age of patients and the risk of pelvic floor insufficiency were relatively high, the grade 2 incontinence rate 6 months after surgery was only $7.1 \%$. No patient complained of nocturnal incontinence. The risk of erectile impotence was not investigated in this series. A scarred bladder neck is the most common postoperative complication $[13,14]$. It should be treated by early dilatation with a $24-\mathrm{Fr}$ sound, or an electrical or laser incision. In addition, the urine is alkalinized with citrate to prevent scarring of the bladder neck. The prognosis of bladder neck stricture is usually good. In our case series, it was treated easily using 24-Fr sound dilatation. A PSA nadir of $\leq 0.2 \mathrm{ng} / \mathrm{mL}$ can be achieved in $95 \%$ of cases, which is proof of the efficacy of total TURPC [11,12]. The 5-year PSA recurrence rate was $18 \%$ for stage pT2 cancer, and the 10 year survival rate was $85 \%$ for stage pT3. These results are equivalent to those of similar surgery reported in recent studies [1630]. PSA recurrence occurred in one case in our series although the short follow-up duration. We examined PSA nadir to predict relapse after TURPC [10]. A PSA nadir of $\leq 0.2 \mathrm{ng} / \mathrm{mL}$ was not achieved in 3 cases of the high risk group. Postoperatively, 7 patients including 3 with a PSA nadir $>0.2 \mathrm{ng} / \mathrm{mL}$, and 1 with biochemical recurrence received adjuvant hormonal therapy. Newly developed lymph node or distant metastasis was not observed during the follow-up period.

In conclusion, using total TURPC in all 14 cases in this series, we achieved a complete resection of the prostate gland including cancerous tissues, but excluding the seminal vesicle and lymph nodes, which was comparable to that achieved using other surgical procedures. This is reflected in the PSA nadir, which is in the majority of cases below $\leq 0.2 \mathrm{ng} / \mathrm{mL}$. TURPC avoids the typical risks of extraprostatic access, because the periprostatic tissue is not severed in order to reach the prostate. Therefore, injury to the nerves in the periprostatic tissue can be avoided, reducing the risk of impotence and incontinence. TURPC is also inexpensive and non-invasive, and requires short 
hospitalization and a short surgical time without vesicourethral anastomosis.

\section{CONFLICT OF INTEREST}

No potential conflict of interest relevant to this article was reported.

\section{ACKNOWLEDGEMENTS}

This study was supported by Wonkwang University in 2011.

\section{REFERENCES}

1. Aus G. Current status of HIFU and cryotherapy in prostate cancer-a review. Eur Urol 2006;50:927-34.

2. Vallancien G, Prapotnich D, Cathelineau X, Baumert H, Rozet F. Transrectal focused ultrasound combined with transurethral resection of the prostate for the treatment of localized prostate cancer: feasibility study. J Urol 2004;171(6 Pt 1):2265-7.

3. Poissonnier L, Chapelon JY, Rouvière O, Curiel L, Bouvier R, Martin X, et al. Control of prostate cancer by transrectal HIFU in 227 patients. Eur Urol 2007;51:381-7.

4. Blana A, Rogenhofer S, Ganzer R, Lunz JC, Schostak M, Wieland WF, et al. Eight years' experience with high-intensity focused ultrasonography for treatment of localized prostate cancer. Urology 2008;72:1329-33.

5. Babaian RJ, Donnelly B, Bahn D, Baust JG, Dineen M, Ellis D, et al. Best practice statement on cryosurgery for the treatment of localized prostate cancer. J Urol 2008;180:1993-2004.

6. Pisters LL, Rewcastle JC, Donnelly BJ, Lugnani FM, Katz AE, Jones JS. Salvage prostate cryoablation: initial results from the cryo online data registry. J Urol 2008;180:559-63.

7. Park DS, Oh JJ, Jang WK, Jee SH, Shin HS. Low-dose-rate brachytherapy for low- and intermediate-risk groups of localized prostate cancer. Korean J Urol 2009;50:656-62.

8. Shipley WU, Scardino PT, Kaufman DS, Katan MW. Treatment of early stage prostate cancer. In: Vogelzang NJ, Scardino PT, Shipley WU, Debruyne FM, Linehan WM, editors. Comprehensive textbook of genitourinary oncology. 3rd ed. Philadelphia: Lippincott Williams \& Wilkins; 2006. p. 153-7.

9. Cookson MS, Aus G, Burnett AL, Canby-Hagino ED, D'Amico AV, Dmochowski RR, et al. Variation in the definition of biochemical recurrence in patients treated for localized prostate cancer: the American Urological Association Prostate Guidelines for Localized
Prostate Cancer Update Panel report and recommendations for a standard in the reporting of surgical outcomes. J Urol 2007;177: 540-5.

10. Lange PH, Ercole CJ, Lightner DJ, Fraley EE, Vessella R. The value of serum prostate specific antigen determinations before and after radical prostatectomy. J Urol 1989;141:873-9.

11. Reuter MA, Corredera M, Epple W, Ungemach G, Verger ML, Dietz K. Transurethral resection in prostate cancer, a radical procedure. Experience with 1017 cases. Arch Esp Urol 2008;61:13-26.

12. Reuter MA, Dietz K. Radical transurethral resection of the prostate. An alternative therapy for the treatment of prostate cancer. Urologe A 2009;48:740-7.

13. Eggener SE, Scardino PT, Carroll PR, Zelefsky MJ, Sartor O, Hricak $\mathrm{H}$, et al. Focal therapy for localized prostate cancer: a critical appraisal of rationale and modalities. J Urol 2007;178:2260-7.

14. Rassweiler J, Teber D, Kuntz R, Hofmann R. Complications of transurethral resection of the prostate (TURP)--incidence, management, and prevention. Eur Urol 2006;50:969-79.

15. Michielsen DP, Debacker T, De Boe V, Van Lersberghe C, Kaufman L, Braeckman JG, et al. Bipolar transurethral resection in saline--an alternative surgical treatment for bladder outlet obstruction? J Urol 2007;178:2035-9.

16. Han M, Partin AW, Piantadosi S, Epstein JI, Walsh PC. Era specific biochemical recurrence-free survival following radical prostatectomy for clinically localized prostate cancer. J Urol 2001;166:416-9.

17. Roehl KA, Han M, Ramos CG, Antenor JA, Catalona WJ. Cancer progression and survival rates following anatomical radical retropubic prostatectomy in 3,478 consecutive patients: long-term results. J Urol 2004;172:910-4.

18. Berglund RK, Sadetsky N, DuChane J, Carroll PR, Klein EA. Limited pelvic lymph node dissection at the time of radical prostatectomy does not affect 5-year failure rates for low, intermediate and high risk prostate cancer: results from CaPSURE. J Urol 2007;177: 526-9.

19. Tewari A, Divine G, Chang P, Shemtov MM, Milowsky M, Nanus D, et al. Long-term survival in men with high grade prostate cancer: a comparison between conservative treatment, radiation therapy and radical prostatectomy--a propensity scoring approach. J Urol 2007; 177:911-5.

20. Boorjian SA, Karnes RJ, Viterbo R, Rangel LJ, Bergstralh EJ, Horwitz EM, et al. Long-term survival after radical prostatectomy versus external-beam radiotherapy for patients with high-risk prostate cancer. Cancer 2011;117:2883-91.

21. Walsh PC. Radical prostatectomy for localized prostate cancer provides durable cancer control with excellent quality of life: a struc- 
tured debate. J Urol 2000;163:1802-7.

22. Kao TC, Cruess DF, Garner D, Foley J, Seay T, Friedrichs P, et al. Multicenter patient self-reporting questionnaire on impotence, incontinence and stricture after radical prostatectomy. J Urol 2000; 163:858-64.

23. Penson DF, McLerran D, Feng Z, Li L, Albertsen PC, Gilliland FD, et al. 5-year urinary and sexual outcomes after radical prostatectomy: results from the Prostate Cancer Outcomes Study. J Urol 2008; 179(5 Suppl):S40-4.

24. Penson DF, Rossignol M, Sartor AO, Scardino PT, Abenhaim LL. Prostate cancer: epidemiology and health-related quality of life. Urology 2008;72(6 Suppl):S3-11.

25. Poulakis V, Witzsch U, de Vries R, Dillenburg W, Becht E. Laparoscopic radical prostatectomy in men older than 70 years of age with localized prostate cancer: comparison of morbidity, reconvalescence, and short-term clinical outcomes between younger and older men. Eur Urol 2007;51:1341-8.
26. Rassweiler J, Schulze M, Teber D, Marrero R, Seemann O, Rumpelt J, et al. Laparoscopic radical prostatectomy with the Heilbronn technique: oncological results in the first 500 patients. J Urol 2005; 173:761-4.

27. Trabulsi EJ, Guillonneau B. Laparoscopic radical prostatectomy. J Urol 2005;173:1072-9.

28. Rassweiler J, Stolzenburg J, Sulser T, Deger S, Zumbé J, Hofmockel $\mathrm{G}$, et al. Laparoscopic radical prostatectomy--the experience of the German Laparoscopic Working Group. Eur Urol 2006;49:113-9.

29. Berryhill R Jr, Jhaveri J, Yadav R, Leung R, Rao S, El-Hakim A, et al. Robotic prostatectomy: a review of outcomes compared with laparoscopic and open approaches. Urology 2008;72:15-23.

30. Secin FP, Bianco FJ, Cronin A, Eastham JA, Scardino PT, Guillonneau $B$, et al. Is it necessary to remove the seminal vesicles completely at radical prostatectomy? Decision curve analysis of European Society of Urologic Oncology criteria. J Urol 2009;181:609-13. 